\title{
Effects of Acrylamide on the Reproductive Hormones and Sperm Quality in Male Rats
}

\author{
Okwuonu Uche Christina ${ }^{1}$, Ugo Obinna Daniel ${ }^{2}$ \\ Department of Anatomy, Igbinedion University, P.M.B. 0006, Okada, Edo State, Nigeria
}

\begin{abstract}
Acrylamide is a white odorless crystalline solid which has been ascertained to be found in some overcooked starchy foods. Studies have shown that this chemical substance is extremely hazardous and has toxic effects on humans and animals hence has been subjected to strict use in facilities which store and produce it in large quantities. The present study was carried out to investigate its effect on the reproductive hormones and sperm quality of male rats. Study animals were divided into four groups with five animals in each group. Group one served as the control while groups two to four were administered oral acrylamide doses $10 \mathrm{mg} / \mathrm{kg}, 15 \mathrm{mg} / \mathrm{kg}$ and $20 \mathrm{mg} / \mathrm{kg}$ respectively, for a period of four weeks. The results obtained from the study showed that acrylamide administration induced a significant decrease in the serum levels of follicle stimulating hormone and testosterone in the treated study animals compared to the control, while the levels of luteinizing hormone and estradiol increased in the treated study animals compared to the control. Results of the sperm analysis revealed marked morphological abnormalities of sperm cells, decreased motility and low sperm count. This indicates that acrylamide induced deleterious effects on the reproductive hormones and was injurious to the sperm cells and b extension sperm quality of male Sprague-Dawley rats.
\end{abstract}

Keywords: Acrylamide, reproductive hormones, Sprague-Dawley rats and sperm quality

\section{Introduction}

Several food constituents are toxic and cause adverse effects to the body and by extension the general wellbeing of an individual. The most critical part is the lack of knowledge of which constituents of the various types of food and food material we consume that have the ability to cause adverse effects. Acrylamide which is considered as an extremely hazardous substance was recently discovered in some cooked carbohydrate based foods. Since the time of this discovery, a myriad of concerns over the safety of the cooked starchy foods we consume almost on a daily basis and worries over which particular carbohydrate based foods are culprits have arisen. This has also triggered scientific researches on the effects of acrylamide on various systems of the body. Acrylamide is a chemical compound with the chemical formula $\mathrm{C}_{3} \mathrm{H}_{5} \mathrm{NO}$. It is a white crystalline solid, odorless and soluble in water, ethanol, ether and chloroform.Acrylamide have been reported to be a potential human carcinogen, though this is yet to be proven as epidemiological cohort studies are required.Its non-thermal decomposition results in the formation of ammonia but thermal decomposition forms oxides of nitrogen, carbon monoxide and carbon dioxide. It decomposes where oxidizing agents, acids, bases, iron salts and iron are present (Parzefall, 2008). Acrylamide has been found to have several uses ranging from the medical, laboratory to the industrial companies were they are used in the manufacture of polyacrylamide and in water treatment (Ran et al., 2014). Since the discovery of acrylamide in overcooked carbohydrate foods in the year 2002 by an Eritrean Scientist Eden Tareke in Sweden, it has raised concerns to humans as to its ability of causing toxicity to the different systems of the body (Tareke et al., 2002). Acrylamide is suspected to be a carcinogen and this has triggered several studies involving animals, the result of which might not be readily extrapolated to humans. Up until 2014 it was still vague whether or not dietary acrylamide is a risk factor for cancer development (Xuet al., 2014). Acrylamide have been found in several plants and reports from previous studies have shown that $200-600 \mathrm{micrograms} / \mathrm{kg}$ of acrylamide is found in roasted barley tea (Ono et al., 2003). Amongst the numerous sources of acrylamide one of its major sources is from cigarette smoking (Vesper et al., 2007). The probability of the presence of acrylamide in a range of food combinations is high such as black olives, prunes, and coffee. It is also evidently found in the reactive combination of asparagine and carbohydrates at high temperature (Mottramet al., 2002; Mucciet al., 2005). However, according to reports from previous studies, some plant constituents or active principles may possess the ability to ameliorate the toxic effects of acrylamide (Adewaleet al., 2015).

Several studies have reported the toxic effect of acrylamide on the reproductive system but few have related its effect on the reproductive hormones to the possible hazards it could cause to the reproductive organs. The aim of this study was to elucidate the possible effects oral doses of acrylamide will have on the levels of reproductive hormones and how that is likely to affect the spermatozoa density, motility and morphology.

\section{Materials and Methods}

\section{Chemical compound}

A $98 \%$ acrylamide with a net quantity of $100 \mathrm{~g}$ and distilled water were purchased from Pyrex-IG Scientific company, Benin City, Edo State Nigeria. The compound was stored in a cool dry place, out of the reach of children because of its hazardous effects until it was needed.

\section{Experimental animals}

Adult male rats, having body weights between 120 to $220 \mathrm{~g}$ were purchased from Igbinedion University animal husbandry. They were kept under standard laboratory conditions and given food and water freely. The animals 


\section{International Journal of Science and Research (IJSR) \\ ISSN (Online): 2319-7064 \\ Index Copernicus Value (2015): 78.96 | Impact Factor (2015): 6.391}

were acclimatized for one week before the experiment was carried out.

\section{Experimental design}

Twenty animals were randomly placed into four groups with each group consisting of five rats each. Three out of the four groups (2-4) were subjected to one month of oral administration of varied doses of acrylamide, while group 1 served as the control group.

The dosage administered to each group is as follows:

- Group $1=2 \mathrm{ml}$ of distilled water (Control group).

- Group $2=10 \mathrm{mg} / \mathrm{kg}$.

- Group $3=15 \mathrm{mg} / \mathrm{kg}$.

- Group 4 = $20 \mathrm{mg} / \mathrm{kg}$.

After the period of one month the rats were sacrificed by cervical dislocation. Blood samples were collected by cardiac puncture into plain capped bottles with the use of a 2 $\mathrm{ml}$ syringe. The blood samples were then centrifuged to separate serum which was then used for hormonal analysis. Through an abdominal incision, the reproductive organs were exposed together with other organs of the body systems. The caudal epididymis were harvested for the sperm analysis and weighed using an electrical weighing balance.

\section{Hormonal analysis}

The blood samples gotten from each rat was centrifuged to separate the serum from the blood cells. The separated sera were then preserved in the refrigerator immediately and used for hormonal profiling after two days. The levels of luteinizing hormone ( $\mathrm{LH})$, follicle stimulating hormone (FSH), Testosterone (T) and Estradiol (EST) for each rat were determined by enzyme linked immunosorbent assay (ELISA) method, using AccuBind ELISA kit (Monobind Inc. CA, USA) and results recorded and eventually analyzed using IBM SPSS version 20 ..

\section{Sperm analysis}

The semen analysis was carried out to check for the effects of the different doses of acrylamide on the sperm cells of the individual rats. Sperm count was done using the method reported by Yokoi and Mayi (2004), where minced epididymis (cauda) was placed in $5 \mathrm{ml}$ of physiological saline and allowed to incubate for 2 mins. The resultant fluid was diluted at 1:100 with a solution of $5 \mathrm{~g}$ sodium bicarbonate as well as $1 \mathrm{ml}$ of $35 \%$ formalin. the resultant solution was taken in bits ( $1 \mathrm{mls}$ at a time) and placed in a Neubauer's counting chamber and number of spermatozoa counted.

Sperm motility was determined using the fluid made from the caudal epididymis which was further diluted with Trisbuffer solution to $0.5 \mathrm{ml}$. an aliquot of the solution was observed under the microscope and mean motility three estimates were used as the final motility score in line with the method of Sonmezet al., (2005).

To carry out the sperm morphology studies, the dilution for motility study was used and further diluted with $10 \%$ neutral buffered formalin. smears were made on glass slides and allowed to dry. Absolute ethanol was introduced and allowed to stay for 5 mins before staining was done and slides viewed under the microscope. The findings were expressed as percentage of morphologically normal and morphologically abnormal spermatozoa (Pal et al ., 2006)

\section{Statistical analysis}

All statistical analysis of data obtained in the course of this study were carried out using the Statistical Package for Social Sciences (SPSS version 20). The results are expressed as mean \pm SEM. Statistical significance was determined by analysis of variance (ANOVA). Significant differences between groups were determined in ANOVA using Duncan posthoc test at $\mathrm{p}<0.05$.

\section{Results}

Effect of acrylamide onreproductive hormones

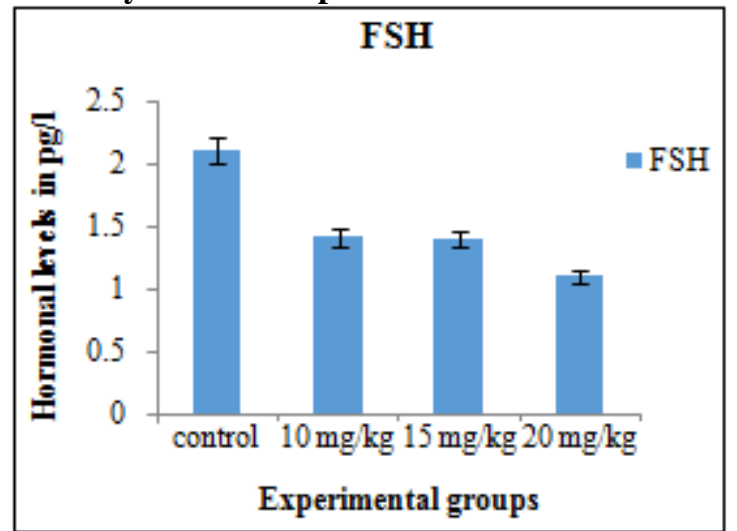

Figure 1: Effect of acrylamide on follicle stimulating hormone (FSH).

The study animals treated with $10 \mathrm{mg} / \mathrm{kg}, 15 \mathrm{mg} / \mathrm{kg}$ and $20 \mathrm{mg} / \mathrm{kg}$ showed a significant dose dependent decrease $(p<0.05)$ in the levels of FSH relative to the control.

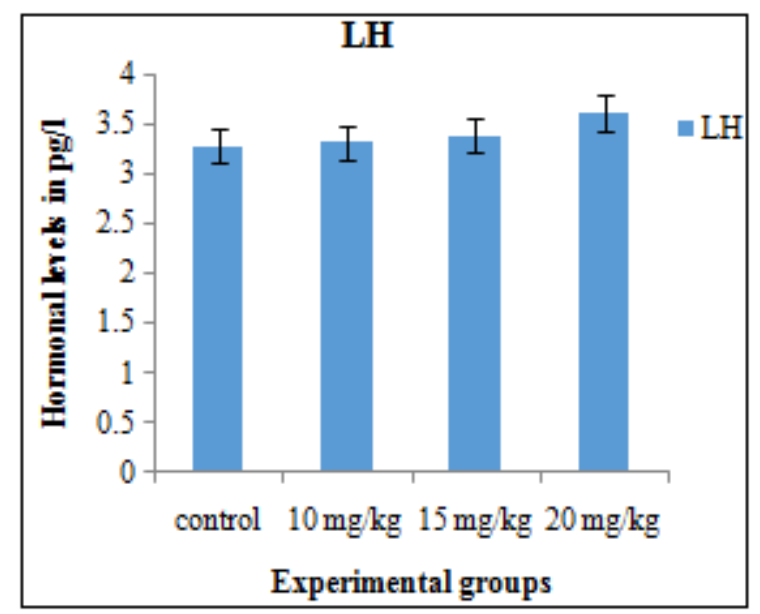

Figure 2: Effect of acrylamide on luteinizing hormone (LH).

The study animals treated with $10 \mathrm{mg} / \mathrm{kg}, 15 \mathrm{mg} / \mathrm{kg}$ and 20 $\mathrm{mg} / \mathrm{kg}$ showed increases that were not statistically significant $(p>0.05)$ in the levels of LH recorded, compared to the control. 


\section{International Journal of Science and Research (IJSR) \\ ISSN (Online): 2319-7064}

Index Copernicus Value (2015): 78.96 | Impact Factor (2015): 6.391

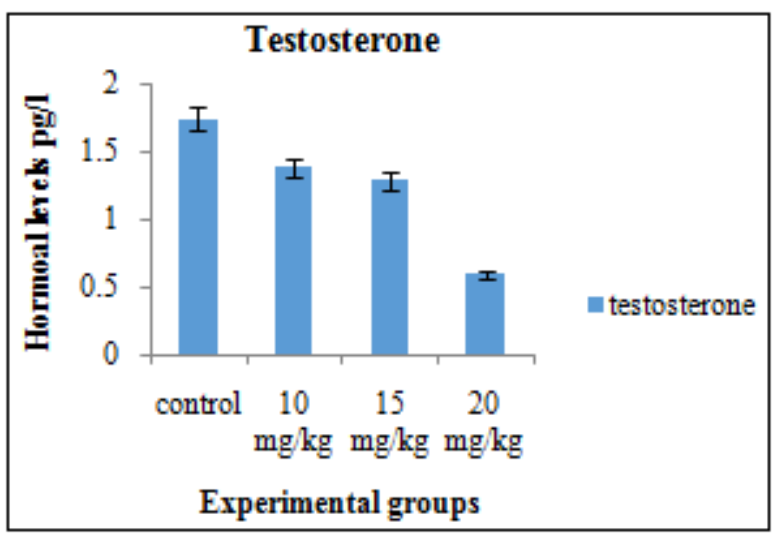

Figure 3: Effect of acrylamide on testosterone

The study animals treated with $10 \mathrm{mg} / \mathrm{kg}, 15 \mathrm{mg} / \mathrm{kg}$ and 20 $\mathrm{mg} / \mathrm{kg}$ showed dose dependent significant decreases $(\mathrm{p}<0.05)$ in the levels of testosterone compared to the control.

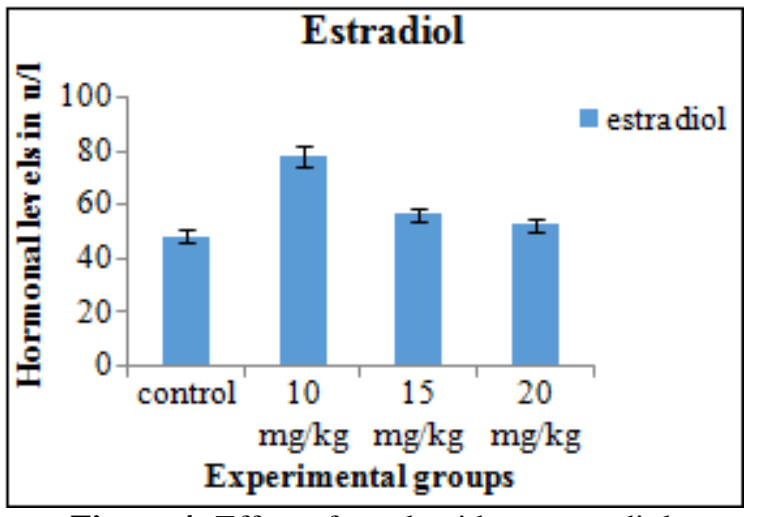

Figure 4: Effect of acrylamide on estradiol

The study animals treated with $10 \mathrm{mg} / \mathrm{kg}$ showed a marked significant increase $(p>0.05)$ in the level of estradiol compared to the control group. But the group treated with 15 $\mathrm{mg} / \mathrm{kg}$ and $20 \mathrm{mg} / \mathrm{kg}$ showed significant increase ( $>0.05$ ) in estradiol level compared to the control.

\section{Effect of acrylamideon sperm count}

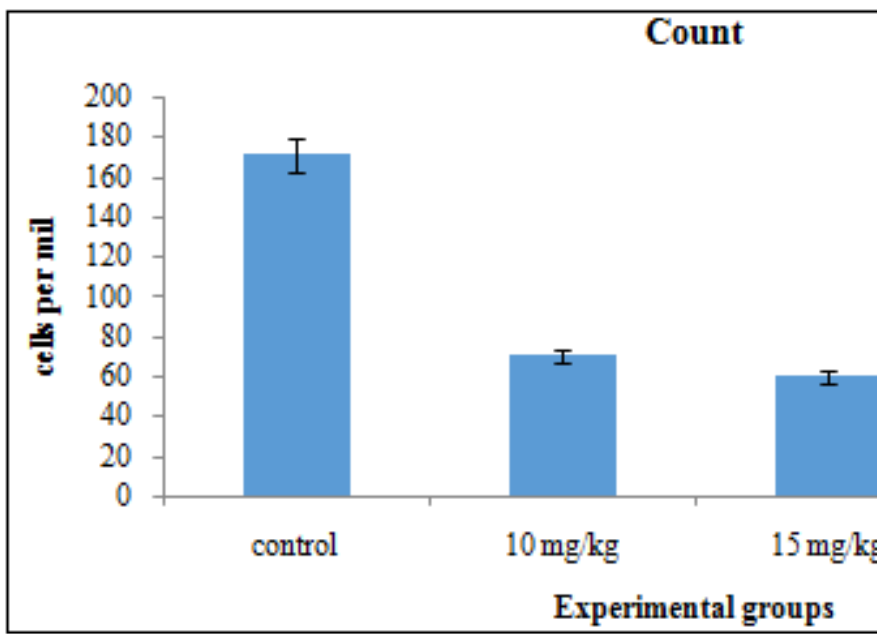

Figure 5: Effect of acrylamide on the sperm count.

The study animals treated with $10 \mathrm{mg} / \mathrm{kg}, 15 \mathrm{mg} / \mathrm{kg}$ and 20 $\mathrm{mg} / \mathrm{kg}$ showed a marked significant decrease $(\mathrm{p}<0.05)$ in sperm count compared to the control group in a dose dependent manner.

\section{Effect of acrylamideon sperm motility}

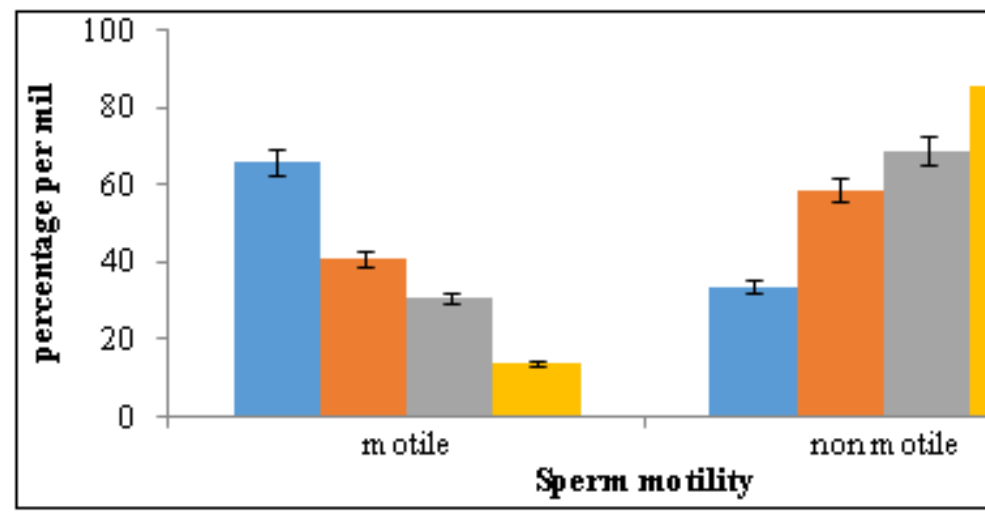

Figure 6: Effect of acrylamide on the sperm motility.

The results of this study shows significant dose dependent decreases $(p<0.05)$ in the percentage of motile sperm cells with a corresponding dose dependent significant increase $(p<0.05)$ in the percentages of non-motile spermatozoa across the experimental groups relative to the control.

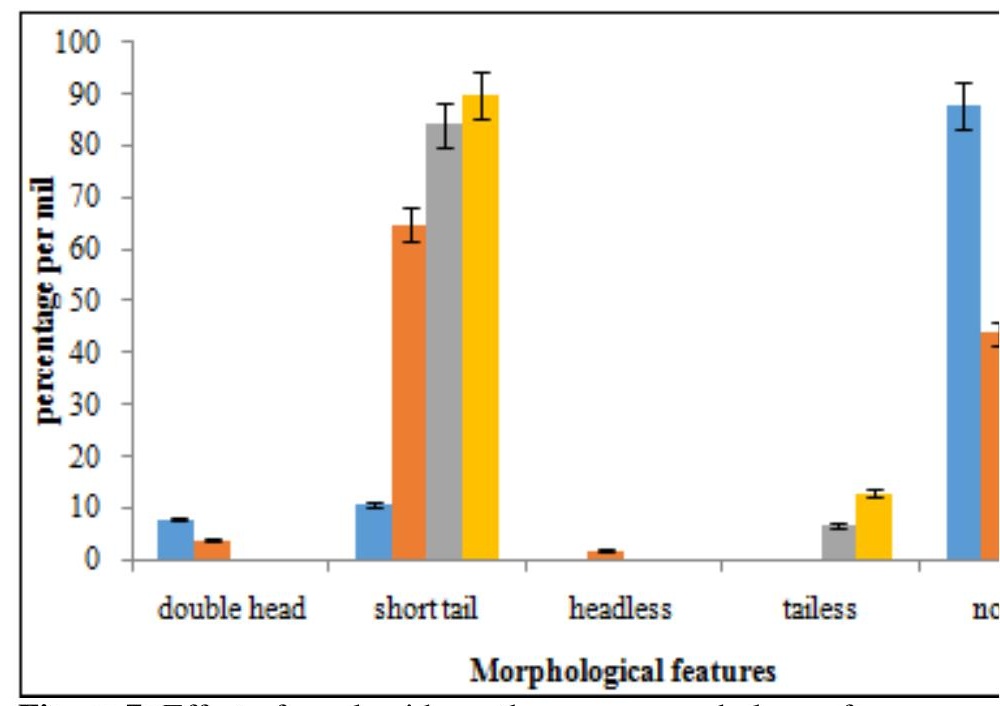

Figure 7: Effect of acrylamide on the sperm morphology of study animals

The results obtained from this study shows that there was a significant increase $(p<0.05)$ in morphologically abnormal sperms across the treated groups relative to control with a corresponding significant decrease $(p<0.05)$ of morphologically normal sperm cells across the treated group compared to the control group.

\section{Discussion}

This work examined the effect of acrylamide on the reproductive hormones and sperm quality of male SpragueDawley rats. Any form of alterations from the normal level of any hormone in the body is an indication that the normal biochemical and physiologic process of the body has been altered, and this can serve as a classical sign of toxicity within the body system. From the study, there was 


\section{International Journal of Science and Research (IJSR) \\ ISSN (Online): 2319-7064}

Index Copernicus Value (2015): 78.96 | Impact Factor (2015): 6.391

significant decrease in the level of follicle stimulating hormone $(\mathrm{FSH})$ and testosterone in the treated animals compared to the control. But, there was a general increase in the level of luteinizing hormone ( $\mathrm{LH})$ and estradiol in the treated animals compared to the control. The decrease in FSH and increase in LH can be attributed to the abnormal function of the anterior pituitary gland caused by atrophy of the brain tissues as a result of acrylamide administration. This decrease in FSH will in turn hinder the process of spermatogenesis which may have led to the abnormalities recorded in the sperm analysis carried out in this study and is a pointer to impairment of fertility. The decrease in testosterone could be as a result of weakness of the Leydig cells caused by excessive secretion of LH as a result of acrylamide administration. This reduction in testosterone level could hinder sex drive and maintenance of secondary sex characteristics in males and may lead to impotency (Mescher, 2013).

The percentage of abnormal sperm cell from the study was seen to be higher in the treated groups in a dose dependent manner compared to the control group. This clearly indicates that acrylamide negatively affected the morphology of the sperm cells. Also, the percentage of non-motile sperm cells, were more in the treated study animals in a dose dependent manner compared to the control group. Sperm count also decreased drastically in the treated study animals in a dose dependent manner compared to the control group. These findings give a clear indication that acrylamide may have the propensity to impair fertility of Sprague-Dawley rats and therefore may also lead to infertility in humans when accumulated in excessive levels. Since the morphology of sperm cells determines the nature of the conceptuse after fertilization, (Mescher, 2013) then abnormal sperm cells can lead to congenital deformities and in severe cases can lead to stillbirth (Sadler, 2010).

In conclusion, acrylamide induced toxic effects on the reproductive system by disrupting hormonal levels andreducing sperm quality of male Sprague-Dawley rats. Further studies on the possible teratogenic effects of acrylamide isrecommended.

\section{References}

[1] Adewale OO, Brimson JM, Odunola OA, Gbadegesin MA, Owumi SE, Isidoro C, Tencomnao T (2015). The Potential for Plant Derivatives against Acrylamide Neurotoxicity.Phytotherapy Research (Review). 29: 978-85

[2] Fishelson, L., Gon, O., Holdengreber, V. and Delarea, Y. (2007).Comparative spermatogenesis, spermatocytogenesis and spermato-zeugmata formation in males of viviparous species of clinid fishes. The Anatomical Record.290 (3): 311-323.

[3] McCollister, D., Oyen, F. and Rowe, V. (1964). Toxicology of acrylamide. Toxicological Application to Pharmacolology. 6 (9): 172-181.

[4] Mescher, A. (2013). Junqueira's basic histology text and atlas. 13 (21): 429-448.

[5] Mottram DS; Wedzicha BL.; Dodson AT. (2002). Acrylamide is formed in the Maillard reaction. Nature.419 (6906): 448-449.
[6] O'Donnell, L., Robertson, K., Jones, M. and Simpson, E. (2001).Estrogen and spermatogenesis. Endocrine Reviews.22 (3): 289-318.

[7] Olesen, P.T; Olsen, A; Frandsen, H; Frederiksen, K; Overvad, K; Tjønneland, A (2008).Acrylamide exposure and incidence of breast cancer among postmenopausal women in the Danish Diet, Cancer and Health Study.International Journal of Cancer.Journal International Du Cancer.122 (9): 2094-100.

[8] Ono, H.; Chuda, Y.; Ohnishi-Kameyama, M.; Yada, H.; Ishizaka, M.; Kobayashi, H.; Yoshida, M. (2003).Analysis of acrylamide by LC-MS/MS and GCMS in processed Japanese foods.Food Additives and Contaminants.20 (3): 215-20

[9] Pal, P. C., Rajalakshmi, M., Manocha, M., Sharma, R. S., Mittal, S. and Rao, D.N. (2006). Semen quality and sperm functional parameters in fertile Indian men.Andrologia.38:20-25.

[10] Pareek, K., Joshi, A., Sanyal, A. and Dighe, R. (2007). Insights into male germ cell apoptosis due to depletion of gonadotropins caused by $\mathrm{GnRH}$ antagonists. Apoptosis. 12 (6): 1085-1100.

[11] Parzefall, W. (2008).Minireview on the toxicity of dietary acrylamide. Food Chemical toxicology 46;13601364

[12] Sadler, T. (2010). Langman's medical embryology. 11 (8): 113-124.

[13] Sonmez, M., Turk, G. and Yuce, A (2005).The effect of ascorbic acid supplementation on sperm quality, lipid peroxidation and testosterone levels of male Wistar rats Theriogenology, 63. 2063-2072

[14] Tareke, E., Rydberg,P., Karlsson, P., Eriksson, S. and Tornqvist, M. (2002). Analysis of acrylamide, a carcinogen formed in heated foodstuffs. Journal of Agric Food Chemistry.50 (1025): 4998-5006.

[15] Vesper, H. W.; Bernert, J. T.; Ospina, M.; Meyers, T.; Ingham, L.; Smith, A.; Myers, G. L. (2007). Assessment of the Relation between Biomarkers for Smoking and Biomarkers for Acrylamide Exposure in Humans.Cancer Epidemiology Biomarkers \& Prevention.16 (11): 2471-2478

[16] Yokoi, K. and Mayi, Z. K. (2004).Organ apoptosis with cytotoxic drugs, Toxicology. 290: 78-85.

[17] Xu, Y., Cui, B., Ran, R., Liu, Y., Chen, H. and Kai, G. (2014).Risk assessment, formation and mitigation of dietary acrylamide: current status and future prospects. Food Chemistry Toxicology.69 (914): 12. 